\title{
Portfólios reflexivos: construindo competências para o trabalho no Sistema Único de Saúde
}

\author{
Rosângela Minardi Mitre Cotta, ${ }^{1}$ Érica Toledo de Mendonça ${ }^{2}$ \\ e Glauce Dias da Costa ${ }^{3}$
}

Como citar Cotta RMM, Mendonça ET, Costa GD. Portfólios reflexivos: construindo competências para o trabalho no Sistema Único de Saúde. Rev Panam Salud Publica. 2011:30(5):415-21.

RESUMO Objetivo. Avaliar a experiência inovadora de educação por competências através de portfólios para a formação de profissionais que atuarão no Sistema Único de Saúde (SUS) no Brasil. Métodos. Utilizou-se a pesquisa qualitativa como modelo de abordagem. Realizou-se a análise documental de 25 portfólios produzidos nos anos de 2008, 2009 e 2010 na disciplina de Políticas de Saúde na Universidade Federal de Viçosa, Minas Gerais, Brasil, com o objetivo de verificar se esse método permitiu a aquisição das competências de aprender a ser (atuar com autonomia, juízo, responsabilidade pessoal); aprender a conhecer (assimilar conhecimentos científicos e culturais gerais e específicos, que se completarão e atualizarão ao longo da vida); aprender a fazer (adquirir procedimentos que ajudem a enfrentar dificuldades na vida e na profissão); e aprender a conviver e a trabalhar com outros (compreender melhor os demais, o mundo e suas inter-relações).

Resultados. Observou-se um envolvimento com as atividades propostas, destacando-se a gestão da informação (busca ativa, seleção, análises críticas, resenhas, sinteses e avaliação da informação). Houve uma gradativa abertura ao pensamento crítico, integrando novas dimensões à visão inicial dos estudantes sobre o SUS, que passou do foco na doença e na cura para um foco em saúde e prevenção, e de uma visão do SUS como modelo teórico para a visão de um projeto possível e em construção.

Conclusões. O uso dos portfólios possibilitou a formação de profissionais de saúde-cidadãos, com ênfase acadêmica, pedagógica e prática. Isso indica que a universidade e o docente podem orientar-se ao desenvolvimento da capacidade de decisão e pensamento reflexivo dos estudantes.

Palavras-chave Materiais de ensino; ensino; educação baseada em competências; Brasil.

Os debates atuais acerca das metodologias inovadoras de ensino-aprendizagem vêm imbuídos da necessidade de reflexão e de revisão das práticas profissionais, num cenário no qual predominam

\footnotetext{
1 Universidade Federal de Viçosa (UFV), Programa de Inovação em Docência Universitária da Área da Saúde (PRODUS), Viçosa (MG), Brasil. Correspondência: rmmitre@ufv.br

2 UFV, Departamento de Medicina e Enfermagem, Viçosa (MG), Brasil.

3 UFV, Programa de Pós-Graduação em Ciência da Nutrição, Viçosa (MG), Brasil.
}

vultosas transformações no âmbito da tecnologia e da produção de informação e conhecimento (1). A mudança de foco do processo de educação visa ao fomento do sentido de autonomia, criatividade e responsabilidade, possibilitando que o aluno aprenda a buscar soluções e a resolver problemas profissionais $(2,3)$.

Ao transcender esse debate para o campo da saúde, torna-se importante refletir sobre qual é o perfil profissional desejável na atualidade, em consonância com as Diretrizes Curriculares Nacionais (DCN) brasileiras para os cursos da área da saúde. As DCN preveem mudanças curriculares pautadas no conceito ampliado de saúde e na consideração do território dos indivíduos como lócus da prática clínica. A formação profissional deve enfocar as diretrizes e princípios do Sistema Único de Saúde (SUS), ou seja, universalidade, integralidade, equidade, descentralização, participação e controle social e regionalização/hierarquização, 
considerando, assim, as necessidades de saúde individuais e coletivas, reorientando o modelo assistencial com foco na doença na direção de um modelo de produção social da saúde, que valorize a promoção da saúde, salientando-se os seus determinantes sociais (4). Desde essa perspectiva, as DCN dos cursos da área da saúde desafiam as formas cristalizadas tradicionais de ensinoaprendizagem, visando a formação de profissionais-cidadãos engajados na luta pela recuperação da dimensão essencial do trabalho em saúde: a produção de cuidados em resposta às demandas sociais (5).

Assim, utilizar metodologias ativas e inovadoras significa apostar em uma educação que desenvolva processos críticos de ensino-aprendizagem, que desperte a criatividade e se baseie nela, que apresente as situações como problemas a resolver - ou seja, uma formação que se aproxime tanto quanto possível da vida real $(4,6)$.

Nessa perspectiva, dentre os recursos inovadores do processo de ensinoaprendizagem e de avaliação, destaca-se o portfólio, como instrumento-estratégia de estimulação do pensamento reflexivo. De acordo com Klenowski (7), o portfólio pode ser definido como um conjunto de trabalhos no qual o estudante retrata sua história de vida, seus progressos e realizações, destacando sua participação na seleção e julgamento dos conteúdos procurados, o que promove uma reflexão e o desenvolvimento da capacidade crítica.

Sendo assim, o portfólio apresenta-se como um instrumento capaz de levar o aluno a colecionar suas opiniões, dúvidas, dificuldades, reações aos conteúdos e aos textos estudados e às técnicas de ensino, sentimentos e situações vividas nas relações interpessoais, oferecendo subsídios para a avaliação do estudante, do educador, dos conteúdos e das metodologias de ensino-aprendizagem (4). Em educação, o portfólio apresenta várias possibilidades, tendo como principal fator de aprendizagem a construção pelo próprio aluno ou grupo de alunos. Pouco a pouco, ao longo do semestre letivo, o estudante vai organizando suas produções, as quais evidenciam o seu processo de construção do saber (6-8). Assim, o portfólio se caracteriza como um instrumento de avaliação formativa, por promover uma aprendizagem pautada no feedback professor-aluno, por desenvolver competên- cias e habilidades respeitando o ensino em diferentes contextos (7), focando em resultados centrados no processo, e não na forma pontual e quantitativa utilizada nas avaliações tradicionais.

Frente a isso, o presente estudo teve por objetivo avaliar a experiência inovadora de construção de portfólios coletivos na disciplina de Políticas de Saúde em uma universidade pública brasileira.

\section{MÉTODOS}

Esta pesquisa utilizou a metodologia qualitativa como modelo de abordagem e a análise documental (9) como técnica de investigação. Cellard (10) ressalta a relevância da análise documental pela possibilidade de reconstruções e por permitir o acréscimo da dimensão do tempo à compreensão da dimensão social. $\mathrm{O}$ documento como unidade de análise permite um corte longitudinal que favorece a observação de um processo de maturação ou de evolução de indivíduos, grupos, conceitos, conhecimentos, comportamentos e práticas ao longo de um período (11). O presente estudo é parte de um projeto de inovação em docência universitária e foi aprovado pelo Comitê de Ética em Pesquisa da Universidade onde se realizou o trabalho (Protocolo no. 091/2010).

Realizou-se a análise de portfólios produzidos na disciplina de Políticas de Saúde pelos alunos de graduação dos cursos de Nutrição e Enfermagem da Universidade Federal de Viçosa, Minas Gerais, Brasil. No período do estudo, estiveram envolvidos neste trabalho 165 alunos, divididos em nove turmas e coordenados por dois docentes.

A construção dos portfólios, realizada em equipes, visou ao desenvolvimento das cinco competências descritas por Fallows e Steven (12): habilidade de comunicação em geral; gestão da informação (busca, seleção, análise e avaliação da informação procedente de diversas fontes); habilidades para a utilização de novas tecnologias; trabalho em equipe, ética, reconhecimento da diversidade, exercício da alteridade, resiliência, compaixão, solidariedade, paciência e escuta qualificada; competências pessoais, como gestão do tempo, responsabilidade e planejamento.

Foram inseridos no corpus documental todos os portfólios produzidos nos anos de 2008, 2009 e 2010, compreendendo um total de 25 portfólios, construídos de forma coletiva. Os portfólios eram subdivididos em três partes:

1) Minha trajetória: memórias redigidas no início e no final do semestre. Cada aluno escreveu sobre sua inscrição histórica no mundo e sobre o grupo. Conjuntamente, os membros do grupo também escreveram sobre a percepção que tinham sobre seus colegas (características pessoais, afetos, qualidades ....).

2) Aprendendo com o grupo: todas as atividades orientadas na disciplina e realizadas em grupo que representavam diferentes maneiras de abordar as temáticas das políticas de saúde, por meio dos preceitos teóricos (resenhas, sínteses ou resumos de artigos científicos e de capítulos de livros) e através de narrativas (relatos de experiências vivenciadas nos diferentes cenários de práticas, sob a forma de problema, para discussão em grupo).

3) Espaço de criatividade: espaço livre onde o grupo exercia sua criatividade utilizando charges, poemas, músicas, fotos, desenhos presentes na mídia escrita e eletrônica, bem como criados pelo grupo. Essas atividades eram sempre acompanhadas de reflexões críticas.

Os portfólios foram datados cronologicamente (P2008, P2009, P2010) conforme o ano em que foram desenvolvidos e numerados aleatoriamente (no. 1, no. 2,..., no. 25) de forma a possibilitar uma organização do acervo para posterior análise e apresentação dos dados. Utilizou-se a técnica de análise temática, com recorte do texto em unidades comparáveis, sob a forma de categorização. Para Bardin (13), a categorização tem por finalidade fornecer uma representação simplificada dos dados brutos, que passam a ser dados organizados.

Inicialmente, foi feita uma leitura flutuante dos portfólios para estabelecimento das categorias presentes no corpus documental. Após o agrupamento das categorias, foram formuladas competências adquiridas pelos estudantes com a utilização do portfólio como instrumento de aprendizagem, com base nas proposições do informe da Organização das Nações Unidas para a Educação, a Ciência e a Cultura (UNESCO), elaborado pela Comissão Internacional sobre Educação (14), que recorre ao conceito de competência e concretiza os objetivos 
do sistema educativo em quatro linhas fundamentais: aprender a ser (atuar com autonomia, juízo, responsabilidade pessoal); aprender a conhecer (assimilar conhecimentos científicos e culturais gerais e específicos, que se completarão e atualizarão ao longo de toda a vida); aprender a fazer (adquirir procedimentos que ajudem a afrontar as dificuldades que se apresentem na vida e na profissão); e aprender a conviver e a trabalhar com outros (compreender melhor os demais, o mundo e suas inter-relações).

\section{RESULTADOS}

Durante todo o processo de construção dos portfólios, os docentes responsáveis pela disciplina atuaram como investigadores críticos do que ocorria na sala de aula, orientando e problematizando os textos, artigos, charges, músicas e reflexões do grupo, sempre com o intuito de preservar a autonomia do aluno e resgatar o seu papel como sujeito que busca e constrói o seu próprio conhecimento. Para a análise dos portfólios, consideraram-se todas as construções, reflexões e documentos que os compunham. Assim, a análise mostrou que os portfólios permitiram aos alunos "aprender a ser" através da atividade "Minha trajetória", que possibilitou o autoconhecimento e o reconhecimento pela equipe de trabalho; "aprender a conhecer", através das atividades orientadas de leitura de textos, artigos, reportagens, elaboração de resenhas e sínteses individuais e coletivas e da conexão dessas atividades com vivências ligadas à realidade social e política; "aprender a fazer", através das atividades orientadas e do "Espaço de criatividade"; e "aprender a conviver e a trabalhar em grupo", uma vez que os portfólios foram construídos em equipe.

A análise dos portfólios apontou para um gradativo envolvimento dos estudantes nas atividades propostas, destacando-se a competência relativa à gestão da informação, com busca ativa e avaliação da informação procedente de reportagens e textos selecionados conforme os conteúdos e temáticas a serem trabalhados na disciplina sobre as questões relacionadas ao SUS. O estímulo à criatividade e a busca ativa e crítica das informações disponíveis estimulou nos acadêmicos a geração de ideias novas, variadas e originais. $\mathrm{O}$ processo de construção dos portfólios e sua avaliação ao longo do semestre pe- los docentes evidenciou a evolução do senso crítico dos alunos; de início, por exemplo, eles selecionavam reportagens ou charges que discorriam sobre o SUS geralmente sob o viés negativo, e se portavam de forma acrítica, ressaltando apenas as mensagens explícitas trazidas pela mídia. Gradativamente, à medida que os conteúdos eram trabalhados na disciplina, os alunos foram adquirindo a capacidade de relacionar esses conteúdos e discutir criticamente. Além disso, a criatividade se manifestou, por exemplo, por meio da composição ou pesquisa de músicas, poemas, ou desenhos e imagens que representavam sua "nova" percepção sobre o SUS, possibilitada pela construção dos portfólios, pelo trabalho em equipe, pelo feedback e avaliações contínuas realizadas pelos professores ao longo do semestre letivo, além do exercício da autoavaliação e avaliação pelos indivíduos e grupos.

Paralelamente, trabalhou-se o desenvolvimento das habilidades de comunicação escrita como competência transversal na educação universitária.

A partir daí, optou-se por analisar especificamente as competências "aprender a conhecer" e "aprender a fazer" (tabela 1). Essas foram as duas competências iniciais desenvolvidas com a construção dos portfólios, representadas pelos apartados "Minha trajetória" e "Aprendendo com o grupo".

Em relação à competência "aprender a conhecer", o portfólio mostrou-se como uma importante ferramenta, capaz de estimular a compreensão e o conhecimento sobre o SUS, bem como sobre diversos interesses que interferem na implementação dessa política, como apresentado na tabela 1 e nos depoimentos dos discentes, registrados nos portfólios:

O portfólio foi uma experiência importante [. . .] Passamos a ficar mais atentos ao mundo que nos rodeia, a prestar atenção no nosso cotidiano no que diz respeito a saúde e sistemas sanitários. Músicas, notícias na televisão, reportagens em revistas, filmes . . tudo isso que antes não tinha importância para nós passou a ser visto com outros olhos (P2008, no. 9).

A elaboração do portfólio [. . .] nos proporcionou [. . .] melhor conhecimento do mundo que está ao nosso redor, e a realidade do país em que vivemos [. . .] opiniões e concepções que eu ti- nha e que foram totalmente transformadas [. . .] (P2008, no. 8).

Pela análise dos portfólios, observou-se que, ao problematizar as temáticas referentes ao SUS, muitos estudantes "aprenderam a conhecer", pois mostraram-se capazes de avaliar criticamente os mais diferentes interesses que permeiam a saúde, possibilitando uma visão mais ampliada, pautada na importância de seus determinantes sociais no processo saúde-doença, como mostram os trechos a seguir:

[. . . ] a saúde não pode ser objeto de mercado, pois este tende a excluir os indivíduos de baixa renda que não possuem condições de adquirir o serviço e que mais necessitam dele [. . .] (P2010, no. 2 e no. 4).

Os dois filmes (Um ato de coragem e $\grave{A}$ procura da felicidade) confirmam as seguintes características do modelo neoliberal: excludente, desigual, sem participação social, não possibilitando acesso a toda população, além de não oferecer um serviço integral e mediante a necessidade (P2010, no. 2).

Em relação à competência "aprender a fazer", a busca dos alunos pelas fontes de informação que contribuíram para a reflexão de questões intrinsecamente ligadas à saúde trouxe para o centro o estudante como sujeito do seu processo de aprendizagem (tabela 1).

[. . .] pensar em políticas públicas requer reflexões que se estendam a temas além de moradia, saneamento básico, salário mínimo, merenda escolar, saúde. Antes mesmo de pensar em políticas públicas, se faz importante pensar em seres humanos que se fazem de satisfações, desejos e anseios [...] (P2010, no. 4).

Nesse sentido, ressalta-se a importância do portfólio no desenvolvimento de competências necessárias ao futuro profissional de saúde: cognitiva (reflexão), psicológica (consciência do seu papel profissional) e atitudinal (mudança de postura na formação e prática do aluno baseado nas DCN e na consolidação do SUS) (15).

Outrossim, merece destaque, na análise dos portfólios, a mudança de concepção e a crítica aos métodos e para- 
TABELA 1. Competências e unidades de registro obtidas pela análise dos portfólios produzidos na disciplina de Políticas de Saúde, Universidade Federal de Viçosa (MG), Brasil

Competência/unidade de registro

\begin{tabular}{|c|c|}
\hline \multicolumn{2}{|l|}{ Aprender a conhecer } \\
\hline Gestão da informação & $\begin{array}{l}\text { Seleção, análises críticas, resenhas e sínteses de artigos } \\
\text { científicos e avaliação da informação }\end{array}$ \\
\hline Conhecimento crítico-reflexivo & $\begin{array}{l}\text { Aperfeiçoamento das capacidades de refletir e } \\
\text { compreender as informações, avaliar e atuar sobre elas }\end{array}$ \\
\hline Visão ampliada da saúde & $\begin{array}{l}\text { Percepção da importância dos determinantes sociais no } \\
\text { processo saúde-doença }\end{array}$ \\
\hline Visão ampliada do Sistema Único de Saúde & $\begin{array}{l}\text { Mudança de percepção sobre a política nacional de } \\
\text { saúde, com o despertar dos estudantes para o seu papel } \\
\text { potencial na transformação da imagem do SUS }\end{array}$ \\
\hline \multicolumn{2}{|l|}{ Aprender a fazer } \\
\hline Sujeito do próprio processo de aprendizagem & $\begin{array}{l}\text { Busca, seleciona, lê, analisa, reflete, apreende e constrói } \\
\text { seu conhecimento }\end{array}$ \\
\hline Capacidade de avaliação e de autoavaliação & $\begin{array}{l}\text { Situações vivenciadas pelos estudantes que os levavam } \\
\text { a rever, reconstruir, reestruturar e reelaborar os seus } \\
\text { conceitos e preconceitos }\end{array}$ \\
\hline Habilidades de comunicação escrita & $\begin{array}{l}\text { Interpretação e desenvolvimento da escrita e do estímulo } \\
\text { à criatividade a partir da elaboração de resenhas, } \\
\text { sínteses individuais e coletivas e outros }\end{array}$ \\
\hline Transformação em estudantes-cidadãos & $\begin{array}{l}\text { Emancipação, autonomia e compromisso social e político } \\
\text { dos estudantes }\end{array}$ \\
\hline
\end{tabular}

digmas estabelecidos acerca do SUS e das políticas de saúde. Os alunos relataram que, a todo o momento, viam-se diante de situações que os levavam a rever, reconstruir, reestruturar e reelaborar os seus conceitos e preconceitos, renovando-os constantemente:

Antes eu pensava que profissionais da saúde só poderiam atuar na cura de doenças, mas percebi que a prevenção é a melhor solução [. . .] digo que o SUS é um sonho no qual temos que trabalhar para que ele vire realidade (P2008, no. 7).

A experiência de construção de portfólios, nesse sentido, propiciou um estreitamento na relação entre ensino e pesquisa, por meio do estímulo à busca por artigos técnicos e científicos e materiais didáticos em diferentes bases de dados, correlacionando-os aos assuntos trabalhados em sala de aula e enriquecendo, assim, o aprendizado. Essa experiência também motivou o autoconhecimento e o conhecimento dos colegas de equipe, implicando compromisso do estudante para com o seu meio e estimulando-o a rever e repensar estratégias para a superação dos obstáculos que se interpõem ao desenvolvimento das atividades propostas, o que é demonstrado no depoimento a seguir:
Constatando, nos tornamos capazes de intervir na realidade, tarefa incomparavelmente mais complexa e geradora de novos saberes do que simplesmente a de nos adaptarmos a ela (P2008, no. 1).

A figura 1 ilustra a visão dos estudantes sobre o SUS antes e depois da construção do portfólio coletivo. Romper com o paradigma presente nas práticas sanitárias do SUS, impregnado pela visão biologicista e curativista, requer mudança ativa na formação dos profissionais de saúde. A análise dos portfólios nos permite afirmar que os alunos apreenderam a importância de revisar conceitos e práticas, havendo, portanto, uma aquisição da competência "aprender a conhecer".

Antes a primeira coisa que vinha à minha cabeça quando pensava em SUS era hospital, internação, remédio para os pobres, e hoje vejo que por trás dessas três letras existe muito mais do que isso: vigilância sanitária, prevenção de doenças, dentre outras coisas. [....] (P2008, no. 7).

[. . .] antes de saber sobre saúde pública era muito fácil criticar o sistema de saúde. [. . .] Não vou mais dizer que o SUS é um sistema direcionado a atender os mais pobres, mas que é um sistema que tem como uma de suas diretrizes a universalidade [. . .] (P2008, no. 7).

O antes [do portfólio]: saúde, ausência de doença. Visão do SUS: programa de governo, que atende a população carente. $\mathrm{O}$ depois [do portfólio]: saúde possui um significado mais amplo, não é só ausência de doença, é estar bem fisicamente, psicologicamente, socialmente, estar bem com o ambiente em que se vive (P2010, no. 1).

A construção do portfólio assegurou aos alunos a possibilidade de aprenderem por si mesmos e com o grupo, exercitando ferramentas que geram autonomia e ajudam a gerenciar a sociedade do conhecimento na qual estamos imersos, de forma a poder tomar decisões. Além disso, o portfólio permitiu "aprender a conhecer", pois potencializou a construção do conhecimento com vistas à autonomia dos sujeitos em formação, valorizando o pensamento crítico e independente, consoante com as DCN, numa dimensão que ultrapassa a reprodução de saberes tecnicistas do processo de trabalho em saúde, ampliando e diversificando o olhar e a capacidade de fazer julgamentos.

Há uma evolução positiva no aprendizado e na compreensão da realidade da saúde no Brasil [. . . ] nosso foco mudou da atenção clínica/curativa para a atenção primária à saúde (P2008, no. 2).

A partir da disciplina Políticas de Saúde e com a construção do portfólio, vejo que desenvolvi um pouco mais minha visão crítica não somente em relação às Políticas de Saúde mas também em relação a vários outros assuntos. Fica evidente o processo pelo qual passei: conhecer-reconhecer-aplicar-viver (P2010, no. 4).

[. . . ] O portfólio foi fundamental para que os conhecimentos obtidos na teoria fossem fixados e analisados, e não apenas decorados. ... através dele, nos tornamos pessoas mais capacitadas e preparadas para a vida profissional (P2010, no. 5).

O pensamento crítico se refere à capacidade de ir além dos significados apa- 
FIGURA 1. Visão dos estudantes sobre a Política Nacional de Saúde antes e depois da construção de portfólios na Disciplina de Políticas de Saúde, Universidade Federal de Viçosa (MG), Brasil

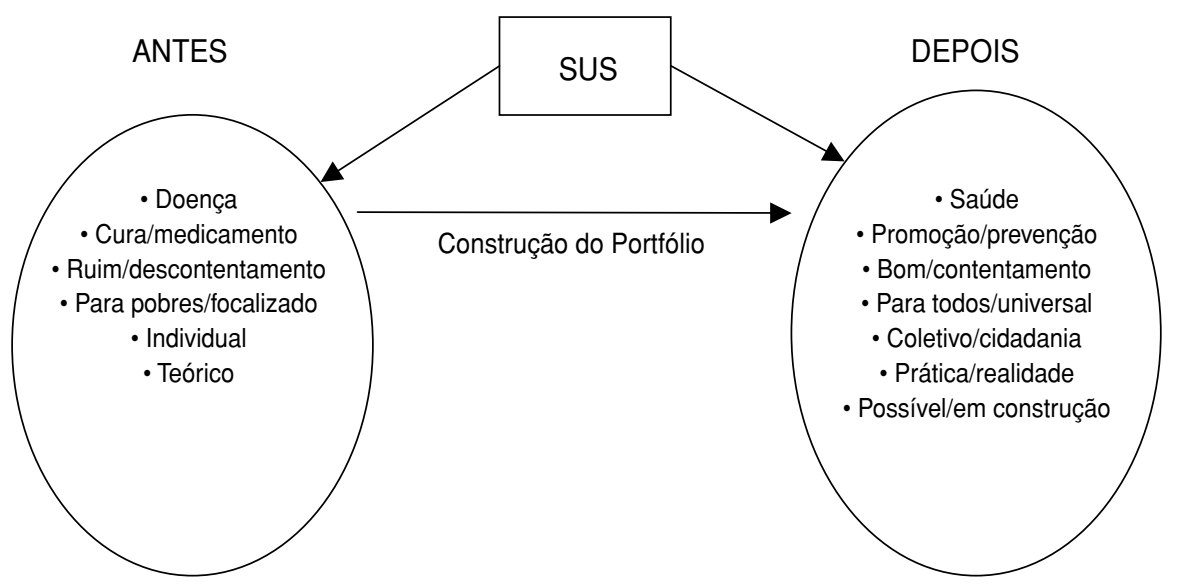

rentes e de dar-se conta do que está por detrás das ideias, argumentos, teorias, ideologias e práticas sociais das quais somos testemunhas cotidianamente (16). A análise dos portfólios, uma estratégia de ensino, aprendizagem e avaliação em Políticas de Saúde, mostrou claramente a aquisição de uma atitude de dúvida e interrogação frente ao que estava posto pela mídia e por outras referências e que contribuiu para um conjunto de mudanças de ideias e criação de juízos de valor próprios sobre as pessoas, políticas e situações (figura 1).

Termino esse portfólio com sentimento de renovação do modo de enxergar a saúde e tudo o que se relaciona a ela (P2010, no. 2).

[. . .] enquanto existir comprometimento e atitude por parte dos profissionais de saúde, dos gestores e dos usuários, sempre existirão árvores e sementes fecundas que serão sempre lançadas no território da saúde brasileira (P2008, no. 6).

Assim, pela análise dos portfólios, destacaram-se dois elementos primordiais: a avaliação crítica feita pelos alunos em relação às informações veiculadas pela mídia impressa e eletrônica sobre o SUS; e a mudança de percepção sobre a política nacional de saúde, com o despertar dos estudantes sobre o seu papel potencial na transformação da imagem do SUS perante a sociedade e na melhoria da situação da saúde do país.

\section{DISCUSSÃO}

A educação centrada em competências possibilita um enfoque que contempla aprendizagens necessárias e substanciais para que o estudante atue de maneira ativa, responsável e criativa na construção de seu projeto de vida, tanto pessoal e social como profissional (3). A competência supõe a interação entre três componentes essenciais, a saber: um conjunto de capacidades (habilidades); um conjunto de conhecimentos gerais procedentes de disciplinas científicas; e uma atitude apropriada para o desempenho de uma função.

A partir da análise realizada, ressalta-se que a busca, seleção, análise e avaliação das reportagens, charges, músicas, poemas e fotografias, dentre outros, veicusobre o SUS, orientadas pelos debates nos grupos, tanto no espaço da sala de aula como nos encontros extraclasse que a construção do portfólio demandava, gradativamente transformaram os estudantes em cidadãos, levando-os a uma mudança de percepção sobre a política nacional de saúde. Esses achados vão ao encontro do estudo desenvolvido por Blanco (15), ao apontar que a sociedade da informação, tão influenciada pelos meios de comunicação, a publicidade e a tecnologia, necessita de cidadãos capazes de avaliar todas as propostas de ofertas que lhes são apresentadas a todo momento.

Cabe perguntar se o sistema educativo que conhecemos fomenta o desenvolvimento de seres humanos profissionais lados pela mídia impressa e eletrônica e cidadãos, com capacidade de decisão própria. Na maioria das vezes, o que se observa é um sistema educativo cuja atuação gera condutas rotineiras e automáticas, dependentes e habitualmente pouco reflexivas. Em contrapartida a essa maneira de educar e aprender, a experiência de 3 anos de construção de portfólios em equipes, apresentada no presente estudo, promoveu um crescimento orientado à emancipação, à autonomia e ao compromisso social e político dos estudantes $(4,16)$.

A indução de mudanças no eixo de formação dos profissionais de saúde requer a articulação de saberes e práticas pautados por orientações sociais que respeitem a diversidade, a formação ética e humanística e que valorizem a integração de saberes e a articulação desses com a realidade vivida. Sob essa ótica, a construção do conhecimento a partir da problematização da realidade intermedeia o resgate da teoria e da prática, estimulando a participação ativa do estudante nesse processo (2).

A representação inicial do objeto de análise - a política de saúde brasileira, o SUS - passa por um processo de reconstituição progressiva, a partir de situações atuais e reais vivenciadas pelo estudante, nas quais as (re)interpretações do mundo e a abordagem teórica se articulam dialeticamente. Os discentes saem de suas posturas de meros receptores acríticos do conhecimento para se tornarem cidadãos capazes de avaliar as situações e propostas que lhes são apresentadas continuamente (4).

Dentro dessa perspectiva, a experiência de construção dos portfólios na disciplina de Políticas de Saúde pode ser considerada uma estratégia inovadora, ao combinar uma formação profissional crítica e reflexiva com questionamento permanente dos conhecimentos cristalizados e rechaço do controle e imposição de pensamentos e ideias - para que surja criatividade, é necessário que haja certo grau de liberdade e autonomia (17).

Outra questão é capacitar os estudantes para desenvolverem tanto os seus conhecimentos quanto a aplicação prática desses conhecimentos, fator de vital importância para a política de saúde. Pretende-se que o estudante chegue a ser autônomo, e isso passa necessariamente pelo fomento da capacidade de analisar, avaliar e emitir juízo. Assim, o desenvolvimento de competências gerais na construção do portfólio coletivo (em sala 
de aula e fora dela) mostrou-se como um meio orientado à formação não só acadêmica, mas também pedagógica, do futuro profissional de saúde-cidadão, e afirmou o papel da universidade e do docente para além da mera transmissão de conhecimentos (18). O portfólio propiciou um aprendizado muito além do adestramento e da profissionalização e resultou necessariamente na integração do conhecimento relativo a como atuar, como conviver e como ser - tudo isso voltado para uma formação ética e humanista $(4,15)$.

Assim, pode-se inferir que a metodologia utilizada na disciplina revelou o potencial de mudança de aptidões e atitudes, atuando fortemente nas esferas afetiva, emocional e vivencial. Estimulou também a cooperação e a integração social entre os alunos, que vivenciaram e experimentaram as dificuldades do trabalho em equipe (6). Verificou-se, dessa forma, que a utilização de portfólios como metodologia de avaliação e estímulo à aprendizagem significativa suscitou nos alunos a reflexão sobre suas experiências e o aprendizado a partir delas, mostrando-se potencialmente instigante e inovadora.

No entanto, é preciso estar atento a algumas limitações na utilização de portfólios coletivos. Um ponto importante refere-se à necessidade de avaliar, além da produção do grupo, a qualidade e o comprometimento de cada aluno. A maioria dos alunos está acostumada com o professor direcionando a educação. Autoavaliação, solicitação de feedback, reflexão e identificação das necessidades individuais e coletivas de aprendizagem, fundamentais para o uso de portfólios, podem ser percebidas como ameaçado- ras, sendo necessárias instruções não apenas sobre a forma de se trabalhar com portfólios, mas também no sentido de ajudar os alunos e demais docentes a entenderem o que é um portfólio e por que ele pode ser usado na educação $(19,20)$.

Além disso, o trabalho com portfólios requer investimento em capacitação dos educadores, destacando-se a importância de os próprios docentes passarem pelo processo de construção de portfólios exercitando, dessa forma, a competência de "aprender fazendo". Outro fator limitante refere-se ao fato de que a construção dos portfólios requer muita dedicação, envolvimento e grande consumo de tempo, tanto dos docentes como dos alunos. Cuidado especial deve ser tomado com sua estruturação, pois, quando se torna rígida e burocrática, pode desviar o foco do trabalho dos alunos, embotando a criatividade e a autonomia. Finalmente, os objetivos da utilização dos portfólios precisam estar muito bem delineados e claros, tanto para os docentes como para os discentes envolvidos no processo $(4,19)$.

\section{CONSIDERAÇÕES FINAIS}

A proposta de construção de portfólios coletivos para a aquisição de competências para o trabalho no SUS baseou-se essencialmente na força criativa e de intercâmbio do trabalho em grupo, onde a educação é um espaço inovador de construção do saber e os alunos são os agentes de sua própria aprendizagem. Assim, é fundamental o enfoque metodológico de caráter interativo e ativo, baseado na comunicação dialógica entre professor-aluno e aluno-aluno.

$\mathrm{O}$ que se observa quando se trabalha com temáticas relacionadas às políticas de saúde é a necessidade de motivar o educando para aprender. Tradicionalmente, a aprendizagem enfoca modos de avaliação baseados em exames centrados na identificação dos resultados de forma pontual, em provas. Como resultado, têm-se alunos que estudam para serem aprovados e não para aprender, postura esta que dificulta a compreensão e a aquisição de competências, bem como o desenvolvimento de atitudes críticoreflexivas que potencializem o aprendizado autônomo. Assim, o portfólio surge como uma estratégia de avaliação com real impacto na motivação e aprendizagem significativa, na qual tanto o professor como o estudante transformam sua forma de ver, pensar e agir.

Destaca-se ainda a importância da formação docente para a implementação das metodologias inovadoras de ensinoaprendizagem, especialmente no tocante ao método de construção do portfólio, bem como a necessidade de motivação dos alunos para engajamento nesse processo.

Por fim, a experiência de construção de portfólios em grupos mostrou-se importante para uma formação em consonância com as DCN e a Política Nacional de Saúde. Nessa oportunidade, os estudantes puderam elaborar e exercitar conteúdos, conhecimentos e experiências, favorecendo o trabalho criativo, coletivo, problematizador e transformador da realidade.

Agradecimentos. $\mathrm{O}$ presente trabalho foi realizado com o apoio da Coordenação de Aperfeiçoamento de Pessoal de Nível Superior (CAPES) (processo no. 23038.009788/2010-78, AUX-PE-PróEnsino Saúde 2034/2010).

\section{REFERÊNCIAS}

1. Mitre SM, Siqueira-Batista R, Girardi-deMendonça JM, Morais-Pinto NM, Meirelle $\mathrm{CAB}$, Porto-Pinto $\mathrm{C}$, et al. Metodologias ativas de ensino-aprendizagem na formação profissional em saúde: debates atuais. Cienc Saude Coletiva. 2008;13(2 supl):2133-44.

2. Ferreira MLSM, Cotta RMM, Lugarinho R, Oliveira MS. Construção de espaço social unificado para formação de profissionais da saúde no contexto do Sistema Único de Saúde. Rev Bras Educ Med. 2010;34(2):304-9.

3. Lizarraga MLSA. Competencias cognitivas en educación superior. Madri: Narcea; 2010.

4. Cotta RMM, Silva LS, Lopes LL, Gomes KO, Cotta FM, Lugarinho R, et al. Construção de portfólios coletivos em currículos tradi- cionais: uma proposta inovadora de ensinoaprendizagem. Cienc Saude Coletiva. Disponível em: http://www.cienciaesaudecoletiva. com.br/artigos/artigo_int.php?id_artigo= 5343 Acessado em 8 de agosto de 2011.

5. Cyrino EG, Toralles-Pereira ML. Trabalhando com estratégias de ensino-aprendizado por descoberta na área da saúde: a problematização e a aprendizagem baseada em problemas. Cad Saude Publica. 2004;20(3):780-8.

6. Noguero FL. Metodologías participativas en la enseñanza universitaria. $2^{\mathrm{a}}$ ed. Madri: Narcea; 2007.

7. Klenowski V. Desarrollo de portafolios para el aprendizaje y la evaluación. $3^{\text {a }}$ ed. Madri: Narcea; 2007.
8. Villas Boas BMF. Portfólio, avaliação e trabalho pedagógico. Campinas: Papirus; 2004.

9. Gil AC. Métodos e técnicas de pesquisa social. $5^{a}$ ed. São Paulo: Atlas; 1999.

10. Cellard A. A análise documental. Em: Poupart J, Deslauriers JP, Grulx LH, Paperriere A, Mayer R, Pires A. A pesquisa qualitativa: enfoques epistemológicos e metodológicos. Petrópolis: Vozes; 2008. Pp. 295-316.

11. Tremblay MY. Initiation à la recherche dans les sciences humaines. Montreal: McGrawHill; 1968.

12. Fallows $S$, Steven G, coord. Integrating key skills in higher education. Employability, transferable skills and learning for life. London: Kogan Page; 2000. 
13. Bardin L. Análise de conteúdo. Lisboa: Edições 70; 2008.

14. Delors J. La educación encierra un tesoro. Madri: Santillana; 1996.

15. Blanco A, coord. Desarrollo y evaluación de competencias en educación superior. Madri: Narcea; 2009.

16. Mejia A, Orduz MS, Peralta BM. ¿Cómo formamos para promover pensamiento crítico autónomo en el aula? Una propuesta de investigación acción apoyada por una herramienta conceptual. Rev Iberoam Educ. 2006;39(6). Disponível em: http://www.rieoei.org/delos
lectores/1499Mejia.pdf Acessado em 8 de agosto de 2011.

17. Teichler U. Sistemas comparados de educación superior en Europa. Marcos conceptuales, resultados empíricos y perspectivas de futuro. Barcelona: Octaedro; 2009.

18. Fernandez-Balboa JM. Recuperando el valor ético-político de la pedagogía: las diferencias entre la pedagogía y la didáctica. Em: Fraile A. Didáctica de la educación física, una perspectiva crítica y transversal. Madri: Biblioteca Nueva; 2004. Pp 315-30.
19. Tartwijk JV, Driessen EW. Portfolios for assessment and learning: AMEE Guide no. 45. Med Teach. 2009;31(9):790-801.

20. Silva RF, Francisco MA. Portfólio reflexivo: uma estratégia para a formação em medicina. Rev Bras Educ Med. 2009;33(4):562-70.

Manuscrito recebido em 14 de novembro de 2010. Aceito em versão revisada em 4 de abril de 2011.

ABSTRACT Objective. To assess the innovative experience of competency education through reflective portfolios for the training of professionals who will work in the Brazilian Unified Health System (SUS).

Learning portfolios as a tool for reflection: building competencies for work in the Unified Health System

Methods. A qualitative research approach was employed. Documentary analysis was carried out covering 25 portfolios produced in the years 2008, 2009, and 2010 in the health policy course at the Federal University of Viçosa, Minas Gerais, Brazil, in order to verify if this method allowed the acquisition of the competencies: learning to be (acting with autonomy, good judgment, personal responsibility); learning to know (assimilating general and specific scientific and cultural knowledge, which will be complemented and updated in the course of life); learning to do (acquiring procedures that will be useful for facing life and work difficulties); and learning to live and work together (better understanding of others, the world, and their inter-relationships).

Results. Students became involved with the proposed activities, especially the management of information (active search, selection, critical analyses, reviews, syntheses, and evaluation of information). There was a gradual opening to critical thinking, integrating new dimensions to the initial vision held by students on the SUS, which moved from a focus on disease and healing to a focus on health and prevention, and from a vision of SUS as a theoretical model towards a view of SUS as a feasible project that is under construction.

Conclusions. The use of portfolios has enabled the education of citizen-health professionals, with academic, pedagogical, and practical emphasis. This indicates that universities and teachers can turn to the development of decision-making capacities and reflective thinking by students.

Key words Teaching materials; teaching; competence-based education; Brazil. 